\title{
Juventudes e organizações da sociedade civil: agenciamentos e os sentidos pedagógicos da atuação das mediações nas margens \\ Lídice Guerrieiro ${ }^{1}$
}

\section{Resumo}

$\mathrm{O}$ artigo analisa dispositivos de gestão e controle de demandas sociais - no caso, a forma de entendimento da "questão social" e as estratégias de enfrentamento - e sua funcionalidade pedagógica para construção de hegemonia através de processos de formação humana e de estratégias para educar conflito social mediadas por organizações da sociedade civil. Dessa forma, questões estruturais são tornadas palatáveis sob os signos da inovação, dos negócios sociais e da cultura do empreendedorismo.

Palavras-chave: Questão social; organizações da sociedade civil; juventudes.

\begin{abstract}
The article analyzes the management and control devices - in this case the form of understanding of the "social question" and coping strategies - and their pedagogical functionality for building hegemony through processes of human development and strategies to educate social conflict mediated civil society organizations. Thus, structural issues are made palatable under the signs of innovation, social business and entrepreneurship culture.
\end{abstract}

Keywords: Social issues; civil society organizations; youths

${ }^{1}$ Doutoranda do Programa de Pós-Graduação em Ciências Sociais (PPCIS) da Universidade do Estado do Rio de Janeiro (UERJ). E-mail: lidguer@gmail.com. 
Recebido em: Julho, 2015

Aceito em: Outubro, 2015

Para citar este artigo:

GUERRIEIRO, Lídice. "Juventudes e organizações da sociedade civil: agenciamentos e os sentidos pedagógicos da atuação das mediações nas margens".In: Revista Intratextos, 2015, vol 6, no1, p. 25-44. DOI: http://dx.doi.org/10.12957/intratextos.2015.17563 


\section{Introdução}

Nos processos de vocalização das demandas sociais em torno da efetivação de direitos políticos, sociais e civis na América Latina, um complexo arranjo de sujeitos e atores sociais vem protagonizando formas de entendimento e atendimento dessas demandas: as parcerias entre mercado, Estado e organizações da sociedade civil local e agências de fomento internacionais.

São desafios práticos e interpretativos acerca das disputas que permeiam a relação entre capital e trabalho na cidade do Rio de Janeiro e a centralidade das favelas nesse processo. A crescente articulação entre sociedade civil, poder público e mercado promove transformações de ordem econômica, política e cultural, vislumbradas como respostas ou ajustes para a atualidade das características do capitalismo globalizado.

A entrada em cena de "novos" protagonistas - organizações da sociedade civil -, ancorados em discursos supostamente apartidários e supraclassistas, organizados em redes com perfil de atuação territorializada, com alto poder mobilizador, vêm representando um terceiro setor capaz de construir uma mediação entre setores da população e mercado. Notamos que é na esfera das formas e práticas culturais, entendidas como construções discursivas norteadoras dos sentidos para as ações, que estão se constituindo as disputas.

Questões estruturais como as desigualdades sociais, as violências e violações, e o acesso democrático à cidade são temas que atravessam e pautam as agendas das organizações da sociedade civil que atuam no sentido de responder a essas questões estruturais. Uma das formas de inserção das organizações da sociedade civil nas favelas é através da realização de projetos. Vislumbram criar tecnologias sociais para a inclusão, para o empoderamento dos sujeitos, para a formação de lideranças. São projetos que atuam construindo conhecimentos, ressignificando olhares sobre o território, ou seja, têm como eixo central a formação humana e as sociabilidades.

Da mesma forma que esses inúmeros projetos podem representar sociabilidades que tenham o potencial de empoderar esses jovens diante da violência do Estado e do tráfico, um olhar mais analítico para os objetivos, metodologias e categorias utilizados por projetos permite estabelecer relações acerca do modus operandi que vem marcando a atuação de três importantes organizações da sociedade civil: Grupo Cultural AfroReggae, Central Única das Favelas (CUFA) e Observatório de Favelas. 
Entender onde, como, quem e o que está em disputa, nos permite mapear os sentidos que atravessam as formas de atuação dos mediadores escolhidos como objeto do presente estudo. Uma busca nas páginas virtuais dessas organizações nos fornece sua geografia de sua atuação - as "margens"2. Seguindo com um questionamento simples, mas não simplificador: por que atuam nesses lugares? É possível construir um campo de ação envolvendo diversos sujeitos: Estado, organizações da sociedade civil, mercado e jovens sujeitos dos projetos.

Pesquisa realizada por Lia Rocha (2013) mostrou que existe um quantitativo considerável de ONGs, grupos culturais e associações realizando uma gama de projetos sociais em favelas e regiões periféricas.

São jovens os principais participantes de grupos e movimentos culturais fortemente identificados com esses territórios (por exemplo, o funk, o hip-hop, o jongo, etc.); e é também jovem o público-alvo principal de ações públicas e privadas realizadas nesses espaços [...]. É evidente que tal escolha não é aleatória ou (somente) ideológica: não apenas os jovens são as maiores vítimas de homicídios dolosos no Rio de Janeiro e como são também os jovens "negros, mulatos, pardos quase brancos" que se engajam em "quadrilhas de traficantes, quadrilhas de assaltantes" e iniciam uma "guerra fratricida" (Zaluar, 2003b). (ROCHA, 2013, pp. 33-34)

A construção de um quadro mais completo necessitaria de um estudo acerca de como os jovens, envolvidos de diversas maneiras nos projetos sociais, vivenciam, negociam e ressignificam os resultados dos "negócios sociais" ${ }^{3}$. O presente recorte não abarca essa etapa.

\footnotetext{
2 A categoria margem é acionada neste contexto para mapear um conjunto de relações e ações sustentadas por processos de identificação de populações e relações sociais mediadas pelo Estado. O conceito desenvolvido pelas autoras Veena Das e Deborah Poole (2008), importante para uma antropologia do Estado, representa um rompimento com abordagens que tomam como premissa a lógica da precariedade e da falta/carência como justificadoras para ausências ou limites acerca dos agenciamentos dos sujeitos subalternizados. A perspectiva relacional adotada pelas autoras permite que a análise social realize abordagens em que as dinâmicas dos sujeitos e seus agenciamentos sejam dotados de uma centralidade, o que visibilidade a práticas e a movimentos do próprio Estado, suas formas de operar, mas também a lógicas que extrapolam a seus agentes, mas que ao mesmo tempo conformam o Estado e suas lógicas de atuação. Dessa forma, o conceito de margem das autoras resgata o caráter dialético e dinâmico do real.

${ }^{3}$ Conceito desenvolvido ao longo do texto. O conceito de negócios sociais acionado no texto agrega sujeitos poder público, empresas, Sebrae, organizações filantrópicas e agências de fomento internacionais - e propostas em torno das possibilidades de articular investidores sociais e empreendedores, estes últimos com um enraizamento na localidade dos investimentos como forma de tornar mais eficiente a aplicação dos projetos, o que permite potencializar os ativos e o retorno do negócio. Visando o aumento da produtividade, os negócios sociais incorporam mão-de-obra de baixa renda nos processos de produção sob o discurso de que é capaz de provocar mudança (que) "gera paz na sociedade pela redução da segregação, pela diminuição da violência e pela esperança de paz" (SANTANA et al., 2015, p.9). O empreendedorismo social de caráter local busca trabalhar o
} 
O objetivo do artigo é apresentar aspectos de um debate acerca dos usos e das possibilidades de interpretação da questão social mediados por organizações da sociedade civil. Categorias acionadas para responder à questão social, presentes nos processos de identificação dos sujeitos, que têm no ator mercado a sua centralidade, são de certa forma, apropriados pelas organizações não governamentais que atuam junto à parcela de jovens moradores de favelas cariocas. A hipótese aqui trabalhada é que determinadas formas de atuação desses mediadores, que operam nas/através/com/para as margens, são informadas por esses processos de identificação, caracterização e nomeação, sendo assim, de algum modo atravessados pela lógica que compreende a integração social pelo mundo do trabalho, mas na condição de subalternidade funcional para a reprodução do capital. O discurso do empreendedorismo pode aqui ser lido desta maneira. De acordo com Virgínia Fontes (2010),

a efetivação capitalista depende da reunião entre estes dois fatores, da exploração do mais-valor e do disciplinamento da população à sua subalternidade, convertendo-a massivamente em força de trabalho, disponível para o capital e incorporada ao mundo mercantil. (FONTES, 2010, p. 217)

No entanto, no contexto de crescente antagonismo entre capital e trabalho com concentração da riqueza, precarização das relações de trabalho, perda de direitos e violência seletiva que atingem a fração da classe trabalhadora mais vulnerável, as possibilidades de integração dão lugar aos conflitos sociais que se expressam de formas diversas.

Lembrando que se os conflitos representam riscos para a necessária estabilidade para os negócios e reprodução do capital, educar o conflito pode representar um duplo papel: controle social e formação humana.

Para Patricia Birman (2008),

Não basta, portanto, apontar a relação entre o discurso sobre as "fábricas de marginais" e a política de repressão ao crime que governo do estado do Rio realiza, creio que é preciso refletir mais claramente sobre os nexos existentes entre as identificações promovidas por este discurso e as políticas governamentais que são praticadas e que possuem as favelas como alvo. (BIRMAN, 2008, p.2)

protagonismo juvenil ao mesmo tempo que deseja uma independência em relação ao fomento exclusivamente empresarial ou Estatal. Procuram por isso realizar formas de financiamento alternativas como o crowdfunding. 
Para tanto, o presente trabalho realizará uma abordagem teórico-conceitual que permita compreender as condições socioeconômicas e discursivas que possibilitam uma atuação articulada entre mercado, Estado e sociedade civil na educação do conflito.

\title{
Reestruturação do capital e a questão social: estratégias para educar o conflito
}

A atual fase do capitalismo monopolista nos coloca desafios interpretativos. Certos recortes analíticos têm levado autores a defender ideias que tomam a atualidade como expressão de uma "nova sociedade", com "novos atores sociais", o que evidenciaria uma "nova questão social".

Pauperização, exclusão, desigualdades sociais são manifestações da "questão social" decorrentes das contradições do modo de produção capitalista e expressam-se de formas particulares em contextos sócio históricos diferentes.

\begin{abstract}
Pensar a "questão social" sem perder de vista a processualidade implica analisar a emergência política de uma questão, adentrar nos processos e mecanismos que permitem que essa problemática tome força pública, que se insira na cena política. [...] É necessário analisar como e quem coloca essa problemática nas agendas dos governos? Quais são os sujeitos coletivos envolvidos? [...] Desvendando os traços constitutivos da "questão social" (aqueles elementos que cruzam os diferentes momentos históricos e as variadas conjunturas sociais) conhecendo e fazendo visível àquilo que permanece, poderemos realmente diferenciar e compreender em que consiste a novidade da "questão social". (PASTORINI, 2004, pp.51-52) ${ }^{4}$
\end{abstract}

Se entendermos o capitalismo não apenas em sua dimensão econômica, mas como uma forma histórica de organizar a vida social, o final dos anos 1990 e a década seguinte, foi um período em que o paradigma neoliberal é rearticulado visando, principalmente, atenuar os

\footnotetext{
${ }^{4}$ José Paulo Netto (2011), tendo como base a análise marxiana da lei geral da acumulação capitalista, analisa a complexidade da anatomia da "questão social" e de seu "caráter de corolário (necessário) do desenvolvimento capitalista em seus todos os seus estágios". Usos de categorias como 'nova' - nova pobreza, nova questão - "do ponto de vista teórico, não apresenta uma só determinação que resista ao exame rigoroso na esteira da crítica da economia política marxiana; do ponto de vista sócio-político, retrocede ao nível das utopias conservadoras do século XIX, proponentes de novos contratos sociais que restabeleçam vínculos de solidariedade no marco de comunidades ilusórias - uma solidariedade naturalmente transclassista e comunidades pensadas com inteira abstração dos (novos) dispositivos de exploração.” (NETTO, 2001, p.48)
} 
impactos para a classe trabalhadora da financeirização das economias. No projeto de crescimento econômico flexível, parcela das estratégias voltadas para as políticas públicas aparecem combinadas com um padrão de intervenção e gestão do Estado na questão social, com uma forte crítica aos programas assistencialistas e uma eloquente defesa da promoção da equidade social entendida como igualdade de oportunidades.

No entanto, há um deslocamento metodológico de qualquer relação sistêmica, estrutural e histórica das crescentes desigualdades na apropriação da riqueza. A emancipação humana fica subordinada à aquisição, pelos indivíduos, de competências e habilidades como forma de potencializar sua atuação na sociedade.

Buscando ampliar o alcance e a eficiência das políticas públicas com esse perfil, estas ganham feições empreendedoras, que pedagogicamente apontam para um redimensionamento do papel da juventude. De jovem como problema social a ser atendido por políticas públicas de controle social, principalmente a juventude em periferias e favelas, toma-se este ator com um dos agentes fundamentais do desenvolvimento; do jovem como problema para o jovem como protagonista na mediação de conflitos (TOMMASI, 2012).

\section{Redimensionando o Estado e as formas de luta}

Se nas décadas de 1970 e 1980, parcela significativa das formas de organização políticas nas periferias, comunidades ou favelas estava orientada para a busca de autonomia em relação aos partidos políticos e o Estado (ZALUAR, 2006), algumas características dessas ações coletivas de moradores, principalmente envolvendo associações de moradores, se modificaram.

Na conjuntura política da década de 1990, o discurso da integração entre a cidade informal e a cidade formal ganha contornos de política pública da mesma forma que a reestruturação neoliberal propõe reformas na regulação das relações sociais, políticas e econômicas. Tais regulações "modernizadas" viabilizam a desintegração dos direitos sociais e estão apoiados no discurso da suposta ineficiência do Estado.

Gabriel Feltran (2010), ao analisar as periferias de São Paulo, reconhece que na década de 1990, apesar do lócus de atuação ser o mesmo, o sentido da mediação das ações coletivas envolvendo moradores e os canais institucionais de diálogo com o Estado mudou. 
As formas de delineamento dos conflitos e as formas de atuação são atravessadas por diversas lógicas.

No contexto da luta política,

a ação política não se limita às disputas entre ações coletivas construídas em terrenos previamente demarcados (movimentos, partidos, conselhos, assembleias, prefeituras etc.) ou aos critérios do jogo democrático; ao contrário, a política nesse contexto se assenta também, , e fundamentalmente, na disputa subjacente à própria instituição destes terrenos e sujeitos - os militantes da favela têm de constantemente forjar sua aparição como sujeitos, lidando com fronteiras impostas pela gestão e, no limite, pela violência. (FELTRAN, 2010, p. 227)

Para Marcia Leite (2013), o Estado se apresenta e atua de modos e formas diferenciadas através de suas instituições. Essa diversidade nas formas de "experiência de Estado" informa os discursos e as representações que fazem referência a uma "ausência" do Estado; lugar de carências, abandonos, de atuação crescente de "dispositivos de exceção que limitam seu acesso à cidade e à cidadania, mantendo-os à margem da cidade.” (LEITE, 2013).

No Brasil, o discurso do social (MARICATO, 1999) dissimula as tensões das práticas administrativas antissociais envolvendo não apenas assimetrias dos investimentos e lógicas de atuação, mas também a funcionalidade da presença e das formas de atuação do Estado. É uma funcionalidade combinada na administração da pobreza onde o arcaico e o pós-moderno se articulam na construção de territorialidades gentrificadas.

Da mesma forma que é preciso entender as representações, os discursos e os lugares de práticas, não podemos descolar da análise os aspectos históricos e estruturais das margens, pois o local contém o universal. "O espaço urbano não é apenas um mero cenário para as novas relações sociais, mas uma instância ativa para a dominação econômica ou ideológica" (MARICATO, 1999, p.150).

É fundamental perceber que o Estado não é o único sujeito a moldar o sentido e a forma com que as relações de poder se configuram. Sua funcionalidade ordenadora e os sentidos acerca da ação do Estado resultam em representações que são frequentemente incorporadas ao imaginário sem passar por crivos minimamente críticos. São representações sobre sujeitos, relações e sociabilidades. Dessa forma, quando acionamos formas de expressão do imaginário social referente à favela, e principalmente os seus moradores jovens, a 
construção dessa alteridade é invadida por imagens associadas à violência, ao tráfico, à marginalidade, a informalidades, a ilegalidades, mais recentemente, criatividade, potência, “viração", inovação, empreendedorismo social.

Sabemos que são usos de processos de identificação interessados e atravessados por disputas, negociações, resistências e conflitos.

\section{Novos contornos da "questão social" e atuação da sociedade civil}

Houve um deslocamento na configuração das relações de poder na contemporaneidade. O elemento articulador da integração social não está mais centralizado na figura do Estado.

Para Licia Valladares (2005), há nas últimas décadas uma importante apropriação em torno das questões que envolvem a reprodução da pobreza urbana tornando a favela "um tema da moda" não apenas para estudos acadêmicos, mas também para ONGs e para uma "produção institucional de pesquisas e relatórios que respondem a uma demanda social específica, tanto técnica quanto política. "(VALLADARES, 2005, p.119).

A forma de apropriação da reprodução da pobreza urbana, sendo um campo diverso, cria um subcampo interpretativo que defende o fim da luta de classes e aponta

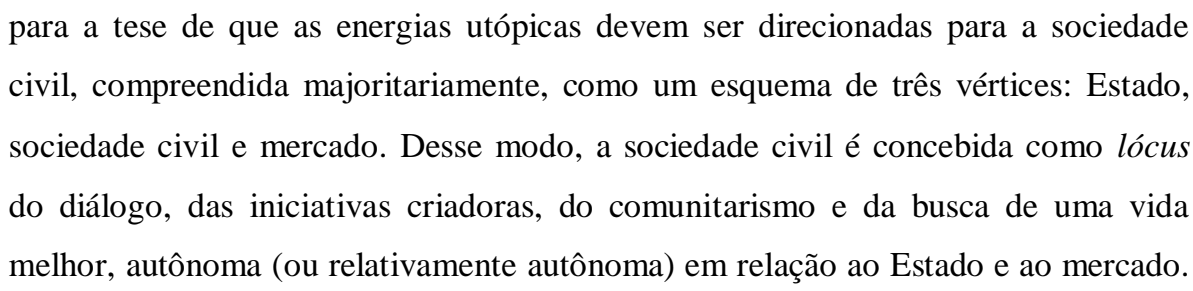

(NEVES, 2010, p.16)

O processo de construção da "favela das ciências sociais" (VALLADARES, 2005) contou com mediações protagonizadas pelo Banco Mundial e pelas Fundações Ford e Rockefeller. Estas desempenharam um papel educador formando intelectuais, fomentando pesquisas e laboratórios de pesquisa social ${ }^{5}$, orientando de modos diversos as formas de construção e abordagens teórico-políticas da questão social, e também do aparelho estatal.

\footnotetext{
${ }^{5}$ Falleiros, Pronko, Oliveira (2010); Ianni (1976); Miceli (1993).
} 
A centralidade da categoria trabalho ganha contornos diversos nos discursos e representações acerca dos problemas urbanos de moradia, transporte e ou saúde pública e a efetivação de direitos, por exemplo, ora fazendo referências às classes perigosas, ora responsabilizando o indivíduo pela pobreza. Há uma multiplicidade de discursos que se justapõem - sanitarista, jurídico, político, econômico.

Valladares (2005) ressalta a produção de uma outra forma de interpretação das causas da reprodução da pobreza urbana como questão social.

A ideia de que imposições objetivas, externas aos indivíduos, poderiam levá-los a uma situação de pobreza, relativizando a importância de sua responsabilidade individual, ao mesmo tempo em que justificava a necessidade de algumas medidas de políticas sociais. (VALLADARES, 2005, p.127)

Interpretações que desmistificam os sentidos da categoria marginalidade contribuíram para a compreensão de outras dimensões das relações entre as distintas territorialidades que compõem as metrópoles. "Da favela-problema à favela-solução" implica em perceber estratégias de construção de habitações, de territorialidades, de novas sociabilidades como resposta, a partir de uma perspectiva integrada, e não dualista, no sentido de se constituírem como sujeitos de direitos.

Buscando desmistificar formas interpretativas acerca da participação popular na construção do seu lugar enquanto sujeito de direitos, a análise realizada por Valladares (2005), aliada à observação participante, identificou mecanismos informais na construção de demandas, nas recusas, nas alianças forjadas e nos delineamentos dos conflitos presentes nos processos de conquistas de direitos ${ }^{6}$. Neste sentido, “o Estado pode ser 'amigo' ou 'inimigo' em função dos interesses em jogo" (VALLADARES, 2005, p.135).

Uma leitura antropológica das margens, apresentada por Veena Das e Deborah Poole (2008), toma a incompletude do Estado como um dado, e dessa forma os lugares de práticas

\footnotetext{
${ }^{6}$ De acordo com Licia Valladares, "a nossa explicação tanto contesta a leitura tradicional dessas relações como puramente hierárquicas, quanto questiona a interpretação da resposta social dos moradores à remoção como um movimento social urbano (Castells, 1980). Preferimos o modelo do free-rider, que salienta os interesses pessoais e as vantagens que podem ser obtidas de uma situação determinada. A prática do 'jeitinho brasileiro' também contribuiu para o desenvolvimento de mecanismos e meios formais e informais para obter benefícios. Se a participação dos favelados foi ativa e criativa, ela também se reconhece mais individual do que coletiva, cada um tentando captar vantagens particulares, sugerindo ser a ideologia utilitária e a ética individualista mais fortes do que a orientação para agir coletivamente" (2005, pp. 135-136).
} 
têm potencialmente o poder de colonizar e, muitas vezes, capturar, suas lógicas de atuação. A realização de análises etnográficas do Estado mostrou que para além dos seus mecanismos de regulação e gestão racional, há uma co-produção do Estado.

Essa estratégia analítica ganha relevância na medida em que dá visibilidade para as lógicas de atuação dos mediadores - as organizações da sociedade civil - e as formas várias de apropriação, captura ou empoderamento dos jovens envolvidos nos projetos.

As possibilidades de respostas para as lógicas de atuação de um Estado educador são atravessadas pelas "práticas e políticas da vida" que redimensionam, distendem ou radicalizam os processos de vocalização diferenciados, mas constitutivos de uma totalidade.

Nesse sentido, é importante que a seguinte questão seja colocada: sobre quais discursos e imagens das favelas agem as organizações estudadas? Sobre as imagens que recriam representações das favelas como territórios portadores de "carências" e "ausências"? Ou sobre a imagem da favela como território apresentado sob o signo do conflito e potente, e por isso seria necessário educar o conflito?

\section{Organizações da sociedade civil, juventudes e os sentidos das identificações que atravessam as formas de enfrentamento das desigualdades sociais}

Diante da crescente indistinção entre o interesse público e privado no plano discursivo, algumas respostas para a "questão social" vêm sendo colocadas pelas organizações da sociedade civil AfroReggae, Observatório de Favelas e CUFA, hibridizando o conceito de sociedade civil, onde supostamente interesses públicos e privados se misturam, se harmonizam e criam condições para operar em um projeto comum de cidade. Nos discursos presentes nos projetos, debates e propostas educativas desaparecem, ou perdem centralidade os conceitos de conflito, classes sociais, desigualdades sociais e dão lugar a protagonismo, potência, disputas de produção de novos olhares e representação, militância e engajamento.

\footnotetext{
Monitores juvenis ou Educadores de pares... Empreendedores Sociais...Protagonistas... Multiplicadores... Articuladores locais... Dinamizadores ou agentes culturais... Essas são algumas denominações pelas quais se identifica os jovens que participam de projetos sociais de ONGs. Essas diferentes nomeações são mais do que formas de rotular: parecem conter expectativas que delineiam perfis de
} 
atuação, orientam um fazer dos jovens e os posicionam em uma relação específica com as práticas sociais, políticas, educativas e/ou culturais sugeridas pelas organizações. (SILVA SOBRINHO, 2012, p.11)

A produção social de identificações e categorizações de pessoas é analisada por Gérard Noiriel (2007) como mecanismos de ordenamento e controle social em contextos diversos. O Estado aparece como um ator altamente interessado na produção de tecnologias identificatórias, o que no contexto estudado também é terceirizado para as ONGs. A produção de perfis pode seguir vários critérios e interesses.

Para Noiriel (2007), isso permite a elaboração de "perfis de risco", por exemplo, que são definidos a partir do lugar de proveniência e do nível de riqueza. O investimento em empreendimentos de marcação identitária produzem nominações que são colocadas de fora para dentro. No entanto, o Estado assim como o campo das ONGs são arenas de disputas onde os sujeitos elaboram e reelaboram as concepções identitária que são relacionais e permeadas por usos diversos em diferentes contextos.

Tais usos vêm permitindo redefinir repertórios identitários e discursos em torno das representações acerca da mobilidade urbana, das favelas, da cidadania, dos direitos, das sociabilidades, por exemplo.

Além de uma vasta produção acadêmica sobre as lutas por cidadania e as disputas por representações acerca das favelas, seus moradores e os problemas sociais enfrentados, novos atores estão disputando, alguns com grande visibilidade, esses processos de identificação: ONGs e setores diretamente ligados ao capital.

Importante perceber que tal processo obviamente não é desinteressado e pode significar novas formas de entendimento da "questão social", incluindo o conceito de cidadania que tanto pode apontar para o caminho da luta política quanto pode apontar para um conceito com as cores do mercado.

É o caso da construção de "novas identidades" para a cidade a partir da visibilidade e de outras formas de reconhecimento das denominadas "sociabilidades subterrâneas"7. Pensar

\footnotetext{
7“Denominam-se sociabilidade subterrâneas as formas de vida social que se tornam invisíveis aos olhos da sociedade por conta de barreiras geográficas, econômicas, simbólicas, comportamentais e culturais. A natureza oculta dessa sociabilidade é socialmente construída por representações dominantes, pelo controle institucional, pela exclusão social e por mecanismos psicossociais, como a negação das condições e dos padrões de vida de
} 
sobre outras bases conceituais a reprodução da pobreza e suas consequências são tentativas que inspiram as ações e metodologias das ONGs.

Estudo mostrando as formas de atuação das organizações AfroReggae e Central Única das Favelas (CUFA) entende que esses atores reúnem um capital social pelo fato de serem originárias de "dentro das favelas" e por utilizarem

a arte, o esporte e o exercício da cidadania para transformar comunidades marginalizadas e estabelecer linhas de intercâmbio e de comunicação entre estas e a sociedade em geral. Uma questão central para o estudo foi compreender a capacidade para agir em contextos de privação, como surgem ações positivas para mudança e quais são suas condições de possibilidade. A pobreza e a marginalização produzem exclusão e sofrimento humano. Contudo, as pessoas que vivem nessas condições contam com competências e habilidades, sabedoria e racionalidade, que lhes permitem resistir à exclusão e promover o desenvolvimento social. Isso requer entendimento e reconhecimento. (JOVCHELOVITCH, 2013, p.20)

Nesse caso, temos um discurso que não faz referência a qualquer causa estrutural da pobreza, apesar de reconhecer sua reprodução e suas consequências perversas para parcela da população. O que deve ser investigado são as formas de enfrentamento da "questão social" da forma como foi desenhada.

A desigualdade social não é o efeito marginal de uma crise do modo de produção capitalista, mas sim, o produto estrutural de seu desenvolvimento. Este último significa que "o aumento da riqueza socialmente produzida, não deriva em maior distribuição, mas em maior acumulação de capital.[...] em absoluto poderemos caracterizar corretamente os fundamentos da pobreza, no capitalismo, sem considerar os processos que fundam a acumulação de capital. (SIQUEIRA, 2014, p.3)

Não obstante, as sociabilidades subterrâneas para se tornarem visíveis e capazes de transpor as "barreiras geográficas, econômicas, simbólicas, comportamentais e culturais" (JOVCHELOVITCH, 2013, p.19) necessitam, para tanto, que os indivíduos reúnam capital

outros. Historicamente associadas à violência, à exclusão e à marginalidade, essas sociabilidade são frequentemente trazidas à tona por erupções que envolvem comportamentos violentos e/ou criminosos". (JOVCHELOVITCH, 2013, p. 19) 
humano e capital social sob a forma de "competências e habilidades, sabedoria e racionalidade" (idem, p. 20).

O conceito de capital social muitas vezes não aparece de forma explícita, mas costuma ser apropriado como um importante ativo na produção de sociabilidades envolvendo o Estado, suas instituições, as populações e crescentemente instituições privadas, entre as quais incluo as organizações não governamentais e organizações diretamente e indiretamente ligadas ao capital privado, seja ele do setor bancário - Banco Mundial, Itaú, Santander entre outros ou de outros ramos do capital - comunicação, petróleo, educação.

Outro recorte referente às formas de enfrentamento das desigualdades sociais é a perspectiva do empreendedorismo. Tomado como realidade inexorável, o empreendedorismo como ideologia se apresenta não como uma possível leitura da realidade, mas como verdade absoluta e única (Cardoso, 2008). Sua aparência de universalidade vem norteando as pautas e as intervenções junto às referidas ONGs, ora de modo explícito, ora de modo diluído em pautas referentes à educação, formação humana, práticas culturais e até mesmo direitos.

Para exemplificar a questão acima, reproduzo parte do discurso de Celso Athayde, fundador da CUFA:

Há tempos percebo as transformações que ocorrem nas favelas impulsionadas pelo empreendedorismo. (...) Foi esse pensamento e a necessidade de criar um ambiente favorável aos negócios dentro das favelas que nos levou a criar a LEC (Liga dos Empreendedores Comunitários).

Cada dia tenho mais convicção que a nova fase da emancipação das favelas passa necessariamente pelo fortalecimento da livre iniciativa e do empreendedorismo. Hoje, as favelas são um mercado consumidor de mais de 50 bilhões de reais. Se as favelas brasileiras fossem um estado da federação, seriam o $5^{\circ}$ maior estado do país. A tal da Nova Classe Média cresceu mais nas favelas do que no restante do Brasil. Simplesmente não dá para ignorar o potencial que este novo mercado significa não só para as grandes empresas, mas principalmente para o empreendedor que mora na favela." 8

De outra forma, o Grupo Cultural Afroreggae produz material informativo e formativo buscando orientar estudantes de diversas idades para a resolução de conflitos a partir do

${ }^{8}$ Disponível em http://cufa.org.br/mudancas-na-cufal. Acesso em 12 de out. 2014. 
desenvolvimento de habilidades socioemocionais ligadas às noções de responsabilidade, superação, avaliação e autoavaliação, trabalho em equipe enquanto requisitos para resolução de conflitos e integração social. ${ }^{9}$ Em sua cartilha Coleção Conversas \#5 A escola tá um saco, posso largar os estudos? ${ }^{10}$, aparecem seis orientações para melhorar a escola, entretanto, o conceito-chave seria avaliação do professor como ferramenta fundamental para uma escola de qualidade.

Os casos citados acima compõem uma das faces de um campo de atuação que conta com outros protagonistas, que intervêm nas favelas e que têm atuado junto às ONGs na realização dos projetos. São empresas, fundações empresariais e institutos ligados e financiados por empresas nacionais e grandes corporações.

De acordo com a Fundação do Gife - Grupo de Institutos, Fundações e Empresas:

os negócios sociais e gestão eficiente por resultados é um caminho sem volta. A combinação entre "negócios" e "causas sociais" tem se revelado uma promissora estratégia de sobrevivência financeira de organizações e de conciliação com causas relevantes à sociedade. ${ }^{11}$ (Gife, p. 11)

Entre as novas tendências estão os negócios sociais, que podem ser entendidos como

empresas que, através da sua atividade principal (core business), oferecem soluções para problemas sociais, utilizando mecanismos de mercado". São, portanto, organizações que têm uma missão de impacto social ou ambiental positivo e utilizam instrumentos de mercado para realizarem essa missão. O lucro gerado pode ser distribuído aos acionistas ou reinvestido no próprio negócio. (Idem, p. 29, grifos dos autores)

Assim é produzido um discurso acerca da forma de atuação das empresas e fundações privadas que supostamente se distancia do assistencialismo e promove uma nova prática

\footnotetext{
9 Um programa bem-sucedido citado pelo estudo é o "Empresários pela Inclusão Social", de Portugal, preocupado em melhorar o rendimento e reduzir o abandono de alunos de $7^{\mathrm{a}}$ e $8^{\mathrm{a}}$ séries. Em grupo, os alunos aprendem a estudar e trabalhar em equipe, treinam suas competências sociais e praticam o controle da ansiedade e do excesso de críticas aos demais". Disponível em http://www.todospelaeducacao.org.br/educacao-namidia/indice/31117/escola-deve-ajudar-a-desenvolver-habilidades-socioemocionais/

${ }^{10}$ Disponível em http://www.afroreggae.org/wp-content/uploads/2014/05/colecaoconversas5.pdf. Acesso em 10 out. 2014.

11 A Fundação Gife é a primeira associação da filantropia na América do Sul. http://www.gife.org.br/arquivos/publicacoes/29/Livro\%20instituto\%20Sabin\%20-\%20Final.pdf. Acesso em 10 out. 2014.
} 
chamada investimento social. Tal discurso diz-se pautado em critérios como "preocupação com o planejamento, monitoramento e avaliação dos projetos; a estratégia voltada para resultados sustentáveis de impacto e transformação social; e o envolvimento da comunidade no desenvolvimento da ação". (DEGENSZJN e RIEBEIRO, 2013, p.19)

O fomento à cultura da doação também aparece no universo de atuação do terceiro setor, mas esta tem contornos bem definidos. De acordo com o Censo Gife 2011-2012 ${ }^{12}$,

\begin{abstract}
A definição da área de atuação é fortemente influenciada pelo caráter empresarial do investimento social brasileiro. Os investimentos em educação, formação de jovens e geração de trabalho e renda, além de ter importância amplamente reconhecida para a transformação social no Brasil, são temas alinhados aos interesses privados das empresas e, em muitos casos, ao negócio. Outros temas alinhados ao negócio têm recebido espaço na agenda do investimento social, como o investimento em desenvolvimento local e em defesa de direitos, especialmente nas indústrias de base.
\end{abstract} (DEGENSZJN e RIEBEIRO, 2013, p.22)

Casos exemplares podem ser encontrados na reportagem sobre "As novas "it-girls" Cinco meninas jovens, todas afrodescendentes, são apresentadas na reportagem como símbolos do "novo" padrão de beleza cuja performance representa "um movimento que cada vez mais une os códigos da cidade partida" (p. 22).

Para a publicitária e integrante do Yunus Negócios Sociais Brasil, Taciana Abreu, “[...] elas pegam o melhor das referências externas, já que a informação está toda disponível na internet, e remixam com as referências de raiz. Da raiz negra, nordestina, de periferia. E, aí sim, criam uma nova estética, que traz consigo o orgulho do território. ” (2015, p. 24). A aparente crítica à essencialização dos sujeitos está combinada com a total ausência de qualquer referência ao racismo na sociedade brasileira, inclusive uma das cinco meninas do grupo é chamada de "morena" pela reportagem: "Keyla Bergamazi pertence à categoria indefinível. Nascida em Vila Isabel, na Zona Norte, a morena de tranças coloridas é, como se diz por aí, uma cidadã do mundo. " (2015, p. 30).

\footnotetext{
${ }^{12}$ Disponível em: http://censo.gife.org.br/bloco5.asp. Acesso em 07 de jan. 2014.

${ }^{13}$ DALE, Joana. Quem são as meninas da periferia que estão 'divando'. In: Revista O Globo, 4/01/2015; pp. 20 31.
} 
São várias as críticas diante de tentativas de "falar por", o que vem abrindo um campo de atuação envolvendo o "falar com". No entanto, quais são as possibilidades e os limites do "falar através" da favela sob o ponto de vista do capital?

Dessa forma os contornos da "questão social” vão se desenhando nas últimas décadas e é neste terreno que os jovens que são moradores de favelas estão se formando, negociando, resistindo e atuando. É um campo com múltiplas possibilidades. A complexidade desses arranjos impõe desafios à análise social.

\section{Considerações finais}

Ao mapear alguns atores estratégicos que atuam em espaços específicos e junto a um público também específico, e destacar os usos de categorias que orientam suas formas de ação, o recorte do artigo objetivou desconstruir uma visão homogênea e simplificadora sobre os sujeitos e suas lógicas de ação, as disputas e os conflitos, ou seja, a ausência de inércia das margens. (DAS \& POLLE, 2008)

As pesquisas realizadas que demonstram a atualização das formas de gestão dos territórios e suas populações, seja redesenhando as favelas como questão social (VALLADARES, 2005), seja criando dispositivos cognitivos, morais (LEITE, 2014), seja ampliando crescentemente os repertórios de mediação (ROCHA, 2014), situam a categoria de análise - margens - como central para a análise social, pois ao tomarem a etnografia como "uma forma de conhecimento que privilegia a experiência, [...] permite introduzir-se nos domínios do social que não são de fácil acesso se se seguem os protocolos formais dos que se servem outras disciplinas" (DAS \& POOLE, p.20).

Entendo que os dispositivos de gestão e controle - no caso, a forma de entendimento da "questão social" e as estratégias de enfrentamento - têm uma funcionalidade pedagógica de formação humana e são estratégicos para educar conflito.

Este trabalho buscou reunir elementos para

Entender as tecnologias de poder específicas através da quais os estados tentam "administrar" ou "pacificar" estas populações, empregando tanto a força como uma pedagogia da conversão dirigida a transformar estes "sujeitos ingovernáveis" em sujeitos legais do Estado. (DAS \& POOLE, 2008, p.11) 
Se por um lado, as ONGs se dizem cada vez menos institucionalizadas, suas formas de atuação, organização e manutenção flertam com o fundo público (dinheiro público), com o mercado via patrocínios, e com formas de financiamento alternativos como o crowdfunding.

O reconhecimento da existência de uma "indústria de mediadores" faz com que, por exemplo, o Observatório de Favelas, em seu discurso em busca de autonomia, enquadre esta categoria como capacidade de criar condições para viabilizar projetos e promover a sobrevivência das organizações, e para isso cria uma rede de colaboradores e empreendedores - o crowdfunding - por exemplo. ${ }^{14}$

Os estudos acerca das respostas para a "questão social" que envolvem atuação da sociedade civil e as parcerias público-privadas propõem múltiplos olhares.

Entendo que as estratégias que envolvem os negócios sociais e suas soluções para a questão social, ao não distinguir interesses públicos do privado podem resultar em formas de individualização das questões sociais e responsabilização do pobre pela sua condição, distanciando-se das causas estruturais de reprodução social das desigualdades.

No plano discursivo, das representações, das identidades e das formas de atuação, há diversas iniciativas contra-hegemônicas, no entanto, é preciso um olhar mais atento para a atuação dos mediadores. O discurso do novo, da ruptura, da criação, da potência, e suas ambiguidades, serão suficientes para pautar lutas políticas que garantam equidades, universalidade e qualidade no atendimento dos direitos sociais? Ou estamos imersos em processos que costuram uma visão supostamente consensual em torno dos interesses de setores do mercado e possibilitam formas de atuação nas margens como "lugares" estratégicos para dar uma face humana ao capital?

Deslocar o conflito e a luta política da disputa pelo Estado pode representar a transformação da cultura da doação em doação de direitos. A atuação educadora do conflito, desempenhado pela tríade mercado, sociedade civil e Estado, vem permitido dar a esses processos formativos as cores do mercado, reconfigurando os sentidos em torno de uma emancipação, que não imponha riscos aos negócios, pois garante acesso a serviços sociais e culturais $^{15}$, mas que não se transformam necessariamente em direitos.

\footnotetext{
${ }^{14}$ http://observatoriodefavelas.org.br/noticias-analises/sustentabilidade-politica-na-era-do-crowdfunding/. Acesso em 30 de dezembro de 2014.

${ }^{15}$ SILVA, Jailson de Souza, BARBOSA, Jorge Luiz, FAUSTINI, Marcus Vinícius. O novo carioca. - Rio de Janeiro: Mórula Editorial, 2012.
} 


\section{Referências bibliográficas}

BIRMAN, Patricia. "Favela é comunidade?" In: Machado da Silva, L.A. (org.) Vida sob cerco: violência e rotina nas favelas do Rio de Janeiro. Rio de Janeiro, FAPERJ/Nova Fronteira, 2008, pp. 99-114.

CARDOSO, Mirian Limoeiro. "Ideologia da globalização e (des)caminhos da ciência social". In: GENTILI, Pablo (org.). Globalização excludente: desigualdade, exclusão e democracia na nova ordem mundial. 5 ed, - Petrópolis, RJ: Vozes; Buenos Aires: Clacso, 2008.

DAS, Veena; POOLE, Deborah. "El estado y sus márgenes. Etnografías comparadas". In: Revista Acadèmica de relaciones Internacionales, núm.8, junio de 2008, Geri-Uam. Disponível em www.relacionesinternacioles.info.

DEGENSZAJN, Andre; RIBEIRO, Pamela. "Panorama do investimento social privado no Brasil". In: DEBONI, Fábio (org.). Investimento social privado no Brasil. Tendências, desafios e potencialidades. $1^{a}$. Edição, Brasília-DF, 2013.

FELTRAN, Gabriel de Santis. "Margens da política, fronteiras da violência: uma ação coletiva das periferias de São Paulo”. In: Lua Nova, São Paulo, 79: 201-233, 2010.

FONTES, Virgínia. O Brasil e o capital imperialismo: teoria e história. - 2. Ed. Rio de Janeiro: EPSJV/Editora UFRJ, 2010.

IANNI, Octávio. Imperialismo e cultura. Petrópolis: Vozes, 1976.

JOVCHELOVITCH, Sandra. Sociabilidades subterrâneas: identidade, cultura e resistência em favelas do Rio de Janeiro. Brasília: UNESCO, 2013.

LEITE, Marcia Pereira. 'Entre a 'guerra' e a 'paz': Unidades de Polícia Pacificadora e gestão dos territórios de favela no Rio de Janeiro". In: DILEMAS: revista de Estudos de Conflito e Controle Social - vol.7 - n 4 - out/nov/dez 2014, pp. 625-642.

UPPs e a segurança dos moradores de favelas. http://www.canalibase.org.br/upps-e-seguranca-dos-moradores-de-favelas/. 19 de fevereiro de 2013. Acesso em 29 de dezembro de 2014.

MARICATO, Ermínia. "Metrópole de São Paulo, entre o arcaico e a pós-modernidade". In: SOUZA, Maria Adélia Aparecida de; LINS, Sonia Correia; SANTOS, Maria do Pilar Costa; SANTOS, Murilo da Costa (orgs.). Metrópole e globalização. Conhecendo a cidade de São Paulo. São Paulo - CEDESP, 1999. Disponível em http://erminiamaricato.files.wordpress.com/2012/09/metropole_globalizacao.pdf. 
MICELI, Sergio. "A aposta numa comunidade científica emergente: a fundação Ford e os cientistas sociais no Brasil”, 1962-1992. In: MICELI, Sérgio (Org.). A Fundação Ford no Brasil. São Paulo: Sumaré, 1993. p. 33-97.

NETTO, José Paulo. Cinco notas a propósito da "questão social". In: Temporalis - Ano 2, n.3 (jan./jun.2001). Brasília:ABEPSS, Grafline, 2001, pp. 41-49.

NEVES, Lúcia Maria Wanderley (org.). A direita para o social e a esquerda para o capital: intelectuais da nova pedagogia da hegemonia no Brasil. - São Paulo: Xamã, 2010.

NOIRIEL, Gérard. Introduction. In: L' identification. Genèse d'um travail d'État. Paris. Éditions Belin, 2007.

PASTORINI, Alejandra. A categoria “questão social” em debate. - São Paulo, Cortez, 2004.

ROCHA, Lia de Mattos. Da "cidade integrada" ao "empreendedorismo": participação e gestão nas margens em tempos de "pacificação" (versão preliminar). $38^{\circ}$ Encontro Anual da Anpocs. Caxambu- Minas Gerais, outubro de 2014.

Uma favela "diferente das outras"? Rotina de silenciamentos e ação coletiva na Favela do Pereirão. - Rio de Janeiro: Quartet: Faperj, 2013.

SANTANA, Ana Lúcia Jansen de Mello; SOUZA, Leandro Marins de. (orgs). Empreendedorismo com foco em negócios sociais. - Curitiba: NITS UFPR, 2015. Disponível em http://www.negociossociais.ufpr.br/geral/livro-empreendedorismo-com-focoem-negocios-sociais/.

SILVA SOBRINHO, André Luiz da. "Jovens de Projetos" nas ONGs: olhares e vivências entre o engajamento político e o trabalho no "social". Dissertação (Mestrado) Universidade Federal Fluminense, Faculdade de Educação, 2012.

SIQUEIRA, Luana. "A pobreza como "disfunção" social: a culpabilização e a criminalização do indivíduo”. In: Argumentum, Vitória (ES), v.6, n.1, p.240-250, jan./jun. 2014.

TOMMASI, Livia de. "Nem bandidos nem trabalhadores baratos: Trajetórias de jovens da periferia de Natal". In: Dilemas: revista de estudos de conflito e controle social. Vol. 5, n.1jan/fev/mar 2012, pp.101-109.

VALLADARES, Licia do Prado. A invenção da favela: do mito de origem a favela.com.Rio de Janeiro: Editora FGV, 2005.

ZALUAR, Alba. "Crime, medo e política”. In: ZALUAR, Alba; ALVITO, Marcos (orgs.). Um século de favela - 5 ed. - Rio de Janeiro: editora FGV, 2006. 